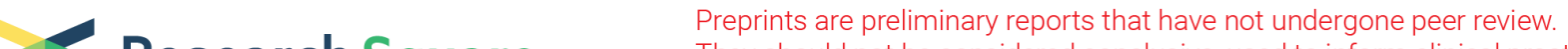 $\begin{array}{ll}\text { Research Square } & \text { They should not be considered conclusive, used to inform clinical practice, } \\ \text { or referenced by the media as validated information. }\end{array}$
}

\section{"We're in Good Hands There." - Acceptance, Barriers and Facilitators of a Primary Care-based Health Coaching Programme for Children With Mental Health Problems: A Qualitative Study (Prima-quo)}

\section{Siona Decke}

Institute for Medical Information Processing, Biometry and Epidemiology, Ludwig-Maximilians-

Universitat München https://orcid.org/0000-0001-6862-2007

\section{Karina Deckert}

BKK Vertragsarbeitsgemeinschaft Bayern

\section{Martin Lang}

Berufsverband der Kinder- und Jugendärzte (BVKJ) e.V. ; PaedNetz Bayern e.V.

Otto Laub

PaedNetz Bayern e.V.

\section{Verena Loidl}

Institute for Medical Information Processing, Biometry and Epidemiology, Ludwig-MaximiliansUniversität München

\section{Lars Schwettmann}

Helmholtz Zentrum München $(\mathrm{GmbH})$ - Institute of Health Economics and Health Care Management (IGM); Department of Economics, Martin Luther University Halle-Wittenberg

\section{Eva Grill ( $\nabla$ eva.grill@med.uni-muenchen.de )}

https://orcid.org/0000-0002-0273-7984

\section{Research}

Keywords: Mental Health Problems, Children and Adolescents, Paediatrician, Health Coaching Programme, qualitative Study

Posted Date: June 25th, 2020

DOI: https://doi.org/10.21203/rs.3.rs-36700/v1

License: (1) This work is licensed under a Creative Commons Attribution 4.0 International License. Read Full License 
Version of Record: A version of this preprint was published at BMC Family Practice on December 1st, 2020. See the published version at https://doi.org/10.1186/s12875-020-01344-1. 


\section{Abstract}

Background:About $17 \%$ of children aged 3-17 years are affected by a mental health problem (MHP). Office-based paediatricians are the first in line to be contacted. Nevertheless, even for less severely affected patients, referral rates to specialised care are constantly high. A major statutory health insurance fund introduced a Health Coaching $(\mathrm{HC})$ programme, including a training concept for paediatricians, standardized guidelines for actions, and additional payments to strengthen primary care consultation for MHP and to decrease referrals to specialized care. The aim of this study was to examine how the $\mathrm{HC}$ is perceived and implemented in daily practice to indicate potential strengths and challenges.

Methods:In 2017 and 2018, a series of guideline-based interviews were conducted by phone with HCdevelopers, $\mathrm{HC}$-qualified paediatricians, parents and patients ( $\geq 14$ years) treated according to the HC programme. Paediatricians were selected from a Bavarian practice network. Parents of patients with the four most common MHP diagnoses were approached by their health insurance. All interviews were recorded and transcribed verbatim. Structuring content analysis derived from Mayring was used for analysis. Sample size was determined by saturation.

Results: 11 paediatricians, 3 developers, 22 parents and four adolescents were included. Families were generally satisfied with paediatric care received in the programme's context. The HC supported paediatricians' essential role as consultants and improved their diagnostic skills. Time and financial restrictions as well as patients' challenging family structures were reported as major barriers to success.

Conclusion: The HC programme is perceived as a facilitator for more patient-centeredcare, however, structural barriers remain.

\section{Contributions To The Literature}

- Lack of specialized training and financial resources for paediatricians has been mentioned as a barrier to effective management of children and adolescents with mental health problems in primary care.

- Although specific training programmes for primary care paediatricians have the potential to optimize management, few studies document how this training is perceived by professionals and patients/parents and how it influences the care process.

- Therefore, we conducted interviews with paediatricians, program developers, patients and their parents to investigate their perception of a training programme implemented by a statutory health insurance funds, and to reveal barriers ofit'simplementation.

\section{Background}

Mental health problems (MHP) of children and adolescents can considerably affect individual health and quality of life as well as performance at school and later professional development (1). Therefore, MHP 
are of high public health relevance in all countries of the world (2). The prevalence of MHP in Germany is high: According to the German Child and Youth Health Survey (KiGGS), around 17\% of children and adolescents aged 3-17 years are affected (3). Developmental disorders, followed by behavioural and emotional disorders are among the most frequent problems encountered in paediatric care (4). Effective and evidence-based therapies for children and adolescents with MHP have been established, e.g. cognitive-behavioural therapy (5) or speech therapy (6). Nevertheless, it has been reported that only $30 \%$ of children and adolescents with MHP in Germany (7) and other industrialised countries access appropriate medical care $(8,9)$.

In Germany, primary care paediatricians are likely the first in line to be consulted for MHP (7), or they detect MHP during the routinely and periodically conducted developmental checks (10). However, depending on the respective diagnosis, a considerable part of children with suspected MHP are subsequently referred to paediatric centres with specific mental health expertise, to speech therapists or to psychotherapy (11). It has been argued that these referral rates are too high because even less severely affected children are referred to specialists although they would not necessarily need specialised care. Time restrictions in primary care practices as well as lack of specialised mental health training for paediatricians have been identified as potential reasons for constantly high referral rates $(12,13)$. As a consequence of referral to specialized services, a number of barriers may impede or delay timely access to professional assessment and therapy. Among these, waiting time, settings that fail to meet parents' and children's needs, long travelling distances and lack of intersectoral communication and treatment have been identified as the most relevant (2). Referral rates could be decreased by interventions targeted at the primary care sector. As one of these promising interventions, enhanced training has been hypothesised to enable primary care physicians to detect mental health problems and to deliver simple interventions (14-18).

With the aim of providing improved integrated care for children and adolescents with MHP, a major German statutory health insurance fund (BKK-LV) in collaboration with a professional association of paediatricians (BVKJ e.V.) has introduced a programme for their insurees targeted at primary care paediatricians (Health Coaching - HC) in 2013 (19). This includes a training concept for paediatricians, standardised guidelines for actions for 16 defined diagnostic entities, and additional fees for paediatricians who undergo this specific training and prescribe and manage insurees according to the guidelines. This approach follows international recommendations and was based on mutual consultations of medical stakeholders [20]. However, the programme has not been systematically evaluated yet. As a result, acceptance and remaining barriers to effective care within the programme are still not understood. The objective of this qualitative study was therefore to investigate how anticipated aims of the $\mathrm{HC}$ are perceived and accepted by paediatricians, affected youth, and their parents. Effectiveness of the programme will be examined elsewhere in an additional quantitative study.

\section{Methods}

\section{Study design}


In a qualitative approach we conducted a series of guideline-based interviews with paediatricians who had completed the $\mathrm{HC}$ training, with parents of children participating in $\mathrm{HC}(<14$ years of age), and with participating adolescents ( $\geq 14$ years of age).

\section{Setting and sample}

$\mathrm{HC}$ is predominantly implemented in Bavaria, one of the largest federal states of Germany with a total of 13 Million inhabitants. Participating paediatricians were members of a Bavarian network of paediatricians ("PaedNetz Bayern"). Over 80\% (750) of the office-based paediatricians in Bavaria are members of PaedNetz Bayern. Currently, a total of 577 members are qualified to participate in the HC programme. Of these, 23 paediatricians consented to participate, three of the consenting paediatricians had also been involved in contract negotiations regarding $\mathrm{HC}$ and in $\mathrm{HC}$ development. Eligible paediatricians were approached by email.

Parents were included if at least one of their children had been diagnosed with one of the four most frequent MHP diagnoses indicated by the ICD code (10th revision), was insured by BKK, and had been included into the programme by a $\mathrm{HC}$ qualified paediatrician. Parents and children were only included if they were aware of the diagnosis (self-statement). Included diagnoses were (1) developmental disorder of speech and language (ICD Codes: F80.0-F80.9), (2) head and abdominal pain (somatoform) (G44.2, G43.0, G43.1, F45.4, R10.4), (3) conduct disorder (F68.8, F91.0-92.9, F94.0-95.9, F98.3-F98.9) and (4) nonorganic enuresis (F98.0). Eligible parents were invited by their health insurance by letter. We interviewed parents of children under 14 and consenting adolescents aged 14 and older. All invited participants received age-appropriate study information with the possibility to contact the study centre in case of questions. In total, 314 parents and ten adolescents declared their interest to be interviewed. By the time of response, one adolescent had reached majority age and was therefore excluded. A total of 122 parents fulfilled our inclusion criteria. Potential participants were then selected based on purposeful sampling, according to principles of maximum variance regarding diagnosis, age, gender, social class, and urban/rural distribution.

All study participants were informed of data protection measures and signed an informed consent form before the beginning of each interview. Participation was voluntary. Paediatricians and families were offered a compensation of 30 and 40 Euro, respectively. The participants were informed about the confidentiality of the interview and the opportunity to stop participation at any time without giving any justification.

Approval from the Ethics Committee and the Data Protection Officer of the Medical Faculty of the LudwigMaximilians-Universität Munich was obtained prior to the start of the study. COREQ (COnsolidated criteria for REporting Qualitative research) checklist was used to support the complete and transparent reporting of our research. The completed checklist is provided (see additional file 2).

\section{Data collection}


Due to geographical distances and feasibility reasons, interviews were conducted exclusively via telephone. The interviews were conducted by one researcher (SD, VL) qualified in qualitative research. Interviews were also randomly and intermittently supervised by a second researcher (SD, VL, EG, all female), for reasons of quality control. Prior to finalising the interview guide we led exploratory interviews with three paediatricians who participated in $\mathrm{HC}$ development. Problems of real-world programme implementation, facilitators and barriers of the programme, and potential need for improvement were reported as most relevant topics. Likewise, exploratory interviews were conducted with eleven participants (21). Prompts and interview guides were subsequently pretested to assess understandability, phrasing and appropriateness of wording. The guide contained questions regarding acceptability of $\mathrm{HC}$, satisfaction with MHP care in the context of HC, quality of interaction with the paediatrician, decision making processes and shared decision making, and potential need for improvement. Interviews were audio-recorded and subsequently transcribed verbatim. Participants did not get the opportunity to review the transcripts. No repeat interviews were carried out. Sample size was determined by saturation. The interview guides and supplementary information to the methodological approach are given in the additional file 1.

\section{Data analysis}

Two researchers (SD, VL) analysed the transcripts independently of each other. Following the structured interview guide, a content analysis approach derived from Mayring $(22,23)$ was applied. Additional data are given in the Online Resource. A deductive and an inductive approach to coding were chosen, which allowed to deductively allocate statements from the interviews to the various main topics ("metacodes") of the interview guideline. Concurrently, the inductive procedure enabled the coding of the interviewees' statements within a priori defined categories while also developing new categories that were not previously defined. Following this, the relevant text passages were systematically identified and assigned to the appropriate meta- and subcodes (Fig. 1).

For example, the parental coding tree with the metacodes "acceptance", "facilitators", "barriers" and "aims" for the HC programme and subcodes such as a "trusting relationship" and "good supply processes" within the metacode "facilitators" were created based on theoretical considerations of the programme objectives before starting the analysis (24). In the course of the coding processes and generalization of the material, new categories were added in the coding tree in cases where a statement could not be successfully assigned to one of the pre-specified codes (inductive approach). After coding a small number of interviews, the coding tree was discussed among authors and adjusted accordingly. Added codes were then either differentiated or removed.

As only four adolescents consented to be interviewed, data saturation could not be reached in this group. We therefore used the same coding system that was applied to the parents' interviews.

F4 (version 2012. Dresing \& Pehl GmbH, Marburg, Germany, http://www.audiotranskription.de/) was used for transcription, MAXQDA 18 (VERBI Software; Consult, Sozialforschung GmbH, Berlin, Germany) was used for coding and analysis. 


\section{Results}

From November 2017 to November 2018, 14 paediatricians, 22 parents and four adolescents were interviewed. These were randomly selected from a total of 23 consenting paediatricians, 314 consenting parents and ten adolescents, until saturation were reached. Five parents who had initially given their consent and were randomly selected, withdrew their participation once they were contacted. Reasons were lack of motivation or time. All consenting adolescents were contacted and 6 withdrew. In two cases, the parents agreed to be interviewed instead. All of the randomly selected paediatricians participated. The characteristics of the interviewees are shown in Table 1. 
Table 1:

Demographic characteristic of paediatricians, parents and adolescents

\begin{tabular}{|c|c|c|c|}
\hline Demographic Characteristics & $\begin{array}{l}\text { Paediatricians } \\
(n=14)\end{array}$ & $\begin{array}{l}\text { Parents } \\
(n=22)\end{array}$ & $\begin{array}{l}\text { Adolescents } \\
(n=4)\end{array}$ \\
\hline Gender (female /male) & $3 / 11$ & $19 / 3$ & $2 / 2$ \\
\hline Age range in years & n.a. & $32-49$ & $14-17$ \\
\hline Age of the child ( $<14$ years) Mean (range) & n.a. & $7.1(3-14)$ & n.a. \\
\hline Diagnosis of the child / adolescent & n.a. & & \\
\hline - $\quad$ Head and somatoform abdominal pain & & 3 & 1 \\
\hline - $\quad$ Developmental disorder of speech \& language & & 5 & - \\
\hline Non-organic enuresis & & 4 & - \\
\hline Conduct disorder & & 5 & 1 \\
\hline Combination of two & & 5 & - \\
\hline None of them/ do not know & & - & 2 \\
\hline Highest educational qualification & n.a. & & n.a. \\
\hline University degree & & 6 & \\
\hline Higher education entrance qual. & & 5 & \\
\hline Intermediate secondary school & & 6 & \\
\hline Secondary school & & 4 & \\
\hline - $\quad$ Other & & 1 & \\
\hline School currently attended by children & n.a. & n.a. & \\
\hline University of applied sciences & & & 1 \\
\hline - $\quad$ Intermediate secondary school & & & 3 \\
\hline Migration background & n.a. & 5 & 0 \\
\hline Population size of place of residence & & & \\
\hline
\end{tabular}




\begin{tabular}{|lccc|} 
Major city $(>100,000)$ & 8 & 7 & 4 \\
\hline Medium sized town $(>20,000)$ & 4 & 4 & - \\
\hline Small town $(>5,000)$ & 2 & 8 & - \\
\hline Country town $(\leq 5,000)$ & - & 2 & - \\
\hline n.a. & - & 1 & - \\
\hline
\end{tabular}

\section{Description of study participants}

Eleven of the 14 interviewed paediatricians were male. Eight practices were located in a major city, six were located in a small or medium-sized town. Duration of interviews was eleven minutes on average (range: 5-23).

Regarding parents, in total 19 mothers (age range 32-49) and three fathers (age range 39-47) were interviewed. Number of children per family ranged from one to three. In five families, the child had a migration background. Migration background was defined based on information about the country of birth of the child and the country of birth and nationality of the parents (children and adolescents who had immigrated from another country and had at least one parent not born in Germany and/or of nonGerman citizenship) (25). The majority of the families $(n=12)$ were inhabitants of a small $(>5.000)$ or medium-sized town $(>20.000)$. Seven families were residents of a major city $(>100.000$ inhabitants). Average duration of interviews with parents was 18 minutes (range: 4-46), with adolescents thirteen minutes (range: $3-17$ ).

\section{Metacodes and subcodes}

Based on the results of the exploratory interviews with $\mathrm{HC}$ developers, we defined four metacodes "acceptance", "facilitators", "barriers" and "aims". For these, we defined 17 subcodes for paediatricians and 13 subcodes for parents/adolescents. All metacodes and subcodes are shown in Fig. 1. In order to facilitate reading, following short forms are used: "DEV" (HC developers), "PAED" (paediatricians), "PAR" (parents) and "ADOL" (adolescents).

\section{Metacode "Acceptance"}

All DEV stated that the aim of the programme was to facilitate diagnosis and treatment of MPH in primary paediatric care to reduce the need for referrals. While this intention was generally well received among colleagues, they also reported rejection and indifference in the beginning among their ranks. PAED perceived their own competence for children with MHP as improved.

I simply can't imagine general routine work without it anymore. (Transcription of Interview partner D5 (DEV), p. 1, lines 14-20)

PAED also had the impression that PAR did not care about being in a specific programme, but appreciated their increased efforts. 
They are happy when the medical conditions we are dealing here with (...) can be treated in the practice of their confidence on an outpatient and on-site basis. (Transcription of Interview partner D5 (DEV), p. 3, lines 86-91)

Accordingly, PAR and ADOL reported that they did not realize that there was a programme specifically designed for their needs.

\section{Metacode "Facilitators"}

DEV stated that flexibility and operability of the programme were planned and implemented right from the start.

We deliberately designed it so simply that everyone can easily cope with it. (Transcription of Interview partner D13 (DEV), p. 3, line 116)

PAED appreciated the additional allocation of resources as a token of trust and valuation.

The fact that the health insurance company recognizes that the basic providers such as a paediatrician can provide some of these specific things and that it is rewarded. (Transcription of Interview partner D14 (PAED), p. 3, lines 71-73)

Repeatedly, PAED reported that the material provided by HC was helpful and facilitated diagnosis and decision-making. They also appreciated the continuing training opportunities.

It allows and structures the approach, may it be in the diagnostics itself in the practice, but also for the diagnosis and, finally, in the decision whether we want and we are able to continue the treatment in the practice. (Transcription of Interview partner D14 (PAED), p. 1, lines 12-16)

PAR and ADOL felt that their PAED allocated a large part of his consultation time to their problems. This was perceived as an indication of high quality of care. PAR mostly reported that they trusted their PAED even with more sensitive issues. Quality of communication and being included in the decision process were appreciated.

I am very satisfied, got a lot of advice and I think, if I go there again now and say: "Well, it has not worked yet", I will be well advised again. At the moment, I cannot think of a better way. (Transcription of Interview partner P13 (PAR), p. 9, lines 348-351)

Interaction between care providers, e.g. between PAED and speech therapists, was positively noted.

It was very uncomplicated. Maybe because of the cooperation of the paediatrician with the speech therapist, that they are so well connected (...) that worked just fine. (Transcription of Interview partner P19 (PAR), p. 9, lines 310-312)

\section{Metacode "Barriers"}


Although substantial financial resources were allocated through the programme, PAED still perceived their opportunities for interaction with the patients as limited. Time and budgetary restrictions were still reported as major barriers to success. Also, as $\mathrm{HC}$ is only one of many managed care contracts PAED reported feeling overwhelmed.

That would be a reason why, also as a health coach, I would refer him or them, because at the moment I can't. (Transcription of Interview partner D13 (DEV), p. 3, lines 92-95)

DEV admitted that a realistic resource estimate should be made before the enrolment of a patient into the HC. PAED reported that it was still difficult to refer patients, and that parents might have problems to follow-up on that referral.

We have too little time to monitor what we recommend to parents (...) This happens very often, that the advice comes to nothing (Transcription of Interview partner D10 (PAED), p. 2, lines 46-51)

We detect children with MHP but it still takes far too long until they receive therapy. (Transcription of Interview partner D13 (DEV), p. 6, lines 205-213)

PAED perceived distinct social disparities, and cultural and linguistic barriers which could not be resolved by the programme. Also, they felt that parents would not necessarily trust their expertise for sensitive issues in MHP.

(...) then the same things will get way more complicated and difficult. (Transcription of Interview partner D5 (DEV), p. 6, lines 194-196)

Many of them like to see us as a cough-runny-nose-flu-doctor only. (Transcription of Interview partner D14 (PAED), p. 3, lines 73-74)

PAR reported feeling reluctant about contacting a physician for MHP of their children, either because this might be too trivial for the paediatrician, or because more specialised help would be needed. However, PAR also reported that they had delayed consulting the PAED because they had underestimated the problems.

Until now we did not suffer so much. I've always thought it would get better somehow. (Transcription of Interview partner P20 (PAR), p. 3, lines 103-109)

PAR explained this by their impression that the PAED acted stressed and in a rush. In this vein, PAED were perceived as hardly encouraging and not participative in treatment decisions, withholding treatment options or disregarding parents' concerns. One mother felt that she was not sufficiently empowered to support her child's therapy more actively.

When you have a problem, you need to convince the doctors to support you. (Transcription of Interview partner P14 (PAR), p. 1, lines 16-17) 
PAR reported problems with secondary and tertiary care, namely long waiting lists for specialist appointments, long distances to the next specialised clinic, limited prescription options of the PAED, and a general lack of insurance coverage for many treatment options. Recommendations were perceived as not compatible with the daily life of a family.

As a working mother with two children who are at school, it is not always easy to implement all supporting measures at home right away. (Transcription of Interview partner P14 (PAR), p. 5, lines 164166)

\section{Metacode "Aims"}

DEV and PAED underlined the need for improved interdisciplinary networking. DEV also mentioned conflicts with specialist care providers and proposed establishing mandatory care pathways. Several detailed recommendations for programme improvement were made, e.g., to facilitate prescription, and to add options to directly strengthen the resources of families (e.g. assistant at home, language support).

...the involvement of other professional groups, for example remedial teacher or people from the sports sector and to involve them early on. (Transcription of Interview partner D7 (DEV), p. 3, lines 99-102)

Care assistants could actually do home visits and have a look at the situation there. (Transcription of Interview partner D3 (PAED), p. 3, lines 106-108)

PAED proposed still higher reimbursement of their services and improved quality control of HC. Universal coverage by all statutory health insurance funds was mentioned.

It should be adequately remunerated and it has to be quality assured. (Transcription of Interview partner D2 (PAED), p. 2 and p3, lines 60-61)

Our goal and our hope are that at some time all insurances will take over this service and will also take for granted that they are responsible for MHP. (Transcription of Interview partner D5 (DEV), p. 6, lines 207-210)

Generally, PAR/ADOL felt sufficiently supported. However, PAR proposed to improve access to services, e.g. by allowing telephone consultations, a better communication between providers, and a more convenient localisation of specialised services.

Specialists for both of these topics are spread quite widely over the country. You really need a connection on site and if there were more cooperation with the paediatricians, that would be great. (Transcription of Interview partner P17 (PAR), p. 11, lines 326-333)

PAR proposed to involve other health professionals such as midwives and alternative practitioners into the programme. Opening treatment options e.g. to include homeopathy, and financial aids were additionally mentioned. 


\section{Discussion}

This qualitative evaluation of a primary care-based programme for children and adolescents with mental health problems revealed high appreciation and acceptance of the programme among paediatricians and families. Adolescents and parents were generally satisfied with the care provided although they did not realise that the programme was specifically targeted to their needs. Furthermore, they mentioned barriers and room for improvement.

Our results are in line with the literature reporting good acceptance of structured MHP programmes in paediatric care, but reports for Germany remain scarce (14-18). However, paediatricians' potential for early detection of MHP in primary care is well documented, based on a high participation rate and acceptance of primary preventive medical examination in children and adolescents $(10,26,27)$. Parents and adolescents in our study reported satisfaction with the care provided and with the involvement in treatment decisions. As parents are the gatekeepers to seeking help for their child, parental perception of barriers and facilitators to MHP treatment access are paramount. In the literature, systemic and structural issues, views and attitudes towards services and treatment, the knowledge and understanding of MHP and the help-seeking process as well as the family circumstances were found to be crucial determinants for parents' decision to seek help $(12,28)$. This is in line with the observations expressed by paediatricians in our study. It indicates that the HC programme should focus more intensely on these barriers. Our interviewed paediatricians made several suggestions to address these barriers. In addition, enhancing parental awareness of MHP and their perception of paediatricians' expertise might reduce the risk of delayed therapy.

A recent meta-analysis found that a lack of providers and resources, extensive waiting lists, and financial restrictions were major barriers for successful MHP management in children and adolescents (12). Quite similarly, paediatricians in our study complained of time and budgetary restrictions. This was unanticipated given that the $\mathrm{HC}$ programme was specifically designed to facilitate access by bringing more resources into the system. Increasing funding for billable services will not necessarily be part of the solution. In contrast, it might be important to strengthen and to expand formal and informal networks as well as systematically and officially include allied health professionals into structured care pathways. For instance, a model programme in Baden Württemberg, Germany, successfully implemented interprofessional quality circles that subsequently increased collaboration and networking (29), or collaborative nurse-led self-management support for primary care patients (30).

The main strength of our study lies in the naturalistic approach and the openness of all interviewees. Despite the sensitive topic, we felt that participants did not hold back their opinions and were eager to talk about their experiences. The inclusion of three co-developers of the $\mathrm{HC}$ among the interviewed paediatricians enriched our findings, too, enabling the distinction of the HC's anticipated goals as compared to its feasibility in everyday practice.

Nevertheless, this study has some limitations. As for all studies relying on qualitative research, interviews are always at least to some degree subject to the assumptions and attitudes of the researchers involved. 
Thus, the assumptions were repeatedly critically examined with respect to the methodological approach and the interpretation of results. However, we are confident that the qualification of interviewers and coders has minimised this potential bias.

$\mathrm{HC}$ covers $16 \mathrm{MHP}$, but the evaluation of the $\mathrm{HC}$ programme initially focused on four selected indications. Arguably, these are the four most common MHP showing up in paediatric practices and responding well to the $\mathrm{HC}$, as specified by paediatricians of PaedNetz Bavaria, but this evaluation needs to be extended. The $\mathrm{HC}$ is currently limited to persons insured at the BKK funds (condition: enrolled in the programme "BKK STARKE KIDS"). Since the BKK is one of the larger statutory health insurance funds with 10.9 (Bavaria: 2.4) of a total of 73.0 million insured persons in Germany(31), the results of our study are most likely to be generalisable. When interpreting the study results, there is a risk of attributing the described differences to the implementation of the HC. It has to be noted that physicians' personal commitment will still be a major driver of positive experiences and high satisfaction of the families.

\section{Conclusion}

Office-based paediatricians are providing low-threshold care and have decisive potential in the care of children and adolescents with MHP. The HC programme currently focuses on paediatricians' resources. Our study showed several strengths but also shortcomings of this approach. A promising future direction would be to involve all necessary care providers to avoid referral bottlenecks. Furthermore, inclusion of parents and their children in decision making should be expanded.

\section{Abbreviations}

$\mathrm{HC}$

health coaching

MHP

mental health problems

PAED

paediatricians

DEV

HC developer

ADOL

adolescents

PAR

parents

\section{Declarations}

Authors' information 
$\mathrm{SD}, \mathrm{MPH}$, is a researcher and $\mathrm{PhD}$ candidate in Medical Research at the Institute for Medical Information Processing, Biometry and Epidemiology, Ludwig-Maximilians-Universität München, Munich, Germany.

$\mathrm{KD}, \mathrm{MPH}$, is an advisor for inpatient care and coordinated several innovation fund projects at BKK Landesverband Bayern, Munich, Germany.

ML, Dr., is a paediatrician located in Augsburg/Bavaria, Germany. He is the national chairman of BVKJ e.V., a professional association of paediatricians in Germany and member of the board of PaedNetz Bayern, a bavarian network of 720 paediatric practitioners.

OL is a paediatrician/allergologist/pulmologist located in Rosenheim/Bavaria, Germany. He is leader of the board of PaedNetz Bayern, a bavarian network of 720 paediatric practicioners.

$\mathrm{VL}, \mathrm{MPH}$ and physio therapist, is a researcher and PhD candidate at the Institute for Medical Information Processing, Biometry and Epidemiology, Ludwig-Maximilians-Universität München, Munich, Germany.

LS, PD Dr., is a health economist, teaching students and working as a research group leader at the Institute of Health Economics and Health Care Management, Helmholtz Zentrum München - German Research Center for Environmental Health (GmbH), Munich, Germany.

EG, Prof. Dr., MHP, is a research epidemiologist, teaching students and working on different topics related to patient-reported outcomes such as quality of life and functioning at the German Centre for Vertigo and Balance Disorders (University Hospital) and at the Institute for Medical Information Processing, Biometry and Epidemiology, Ludwig-Maximilians-Universität München, Munich, Germany.

\section{Ethics approval and consent to participate}

Prior to inclusion, all participants had to sign a written informed consent form. The study was approved by the ethical committee of the Ludwig-Maximilians-Universität München (reference number 17-431) and have therefore been performed in accordance with the ethical standards laid down in the 1964 Declaration of Helsinki and its later amendments. The study was also reviewed by the data protection officer of the Ludwig-Maximilians-Universität München.

\section{Consent for publication}

Not applicable.

\section{Availability of data and material}

Due to the nature of this research, participants of this study did not agree for their data to be shared publicly, so supporting data is not available. MAXQDA 18 (VERBI Software; Consult, Sozialforschung $\mathrm{GmbH}$, Berlin, Germany) was used for coding and analysis. The coding system can be provided on demand. 


\section{Competing interests}

The authors declare that they have no competing interests.

\section{Funding}

This publication was created by a project (PrimA-QuO) funded by the German Innovationsfonds under grant number 01VSF16032.

\section{Authors' contributions}

SD was the principal author of this article. All authors contributed to the study conception and design. Material preparation, data collection and analysis were performed by SD and VL. The first draft of the manuscript was written by SD. All authors read and approved the final manuscript.

\section{Acknowledgments}

The authors acknowledge patients' willingness to participate, support and their valuable feedback in the pilot testing of the guideline for the semi-structured interview. The authors also acknowledge the support of "PaedNetz Bayern e.V." and "BKK Vertragsarbeitsgemeinschaft Bayern" in recruiting children and adolescents as well as paediatricians and inviting them to participate in this study.

\section{References}

1. World Health Organization. Investing in mental health. Evidence for action. Geneva2013.

2. Patel V, Flisher AJ, Hetrick S, McGorry P. Mental health of young people: a global public-health challenge. Lancet. 2007;369(9569):1302-13.

3. Baumgarten F, Klipker K, Göbel K, Janitza S, Hölling H. Der Verlauf psychischer Auffälligkeiten bei Kindern und Jugendlichen - Ergebnisse der KiGGS-Kohorte. Journal of Health Monitoring. 2018;3(1):60-5.

4. Steffen AAM, Holstiege J, Bätzing J. Diagnoseprävalenz psychischer Störungen bei Kindern und Jugendlichen in Deutschland: eine Analyse bundesweiter vertragsärztlicher Abrechnungsdaten der Jahre 2009 bis 2017. In: Versorgungsatlas-Bericht Nr. 18/07. Berlin: Zentralinstitut für die kassenärztliche Versorgung in Deutschland (Zi); 2018.

5. Higa-McMillan CK, Francis SE, Rith-Najarian L, Chorpita BF. Evidence Base Update: 50 Years of Research on Treatment for Child and Adolescent Anxiety. Journal of Clinical Child Adolescent Psychology. 2016;45(2):91-113.

6. Law J, Garrett Z, Nye C. Speech and language therapy interventions for children with primary speech and language delay or disorder. Cochrane Database Syst Rev. 2003(3):Cd004110.

7. Hintzpeter B, Klasen F, Schon G, Voss C, Holling H, Ravens-Sieberer U. Mental health care use among children and adolescents in Germany: results of the longitudinal BELLA study. Eur Child Adolesc 
Psychiatry. 2015;24(6):705-13.

8. Barbato AV, Martine; Rapisarda F, Lora A. Caldas de Almeida, José Miguel EU compass for action on mental health and well-being. Access to Mental Health Care in Europe. Scientific Paper. Funded by the European Union in the frame of the 3rd EU Health Programme (2014-2020). 2016.

9. Access to Mental Health Care

Adolescent Health Highlight

Murphey D, Vaughn B, Barry M. Adolescent Health Highlight: Access to Mental Health Care. 2013.

10. Schmidtke CK, Starker B, Lampert A. Thomas. Inanspruchnahme der

Früherkennungsuntersuchungen für Kinder in Deutschland - Querschnittergebnisse aus KiGGS Welle 2. Journal of Health Monitoring. 2018;3(4):68-77.

11. Fegert JM, Kölch M, Krüger U, Baumann AE. Sachbericht zum Projekt: Versorgung psychisch kranker Kinder und Jugendlicher in Deutschland - Bestandsaufnahme und Bedarfsanalyse. Laufzeit:

01.11.2014 bis 28.02.2017. 2017.

12. O'Brien D, Harvey K, Howse J, Reardon T, Creswell C. Barriers to managing child and adolescent mental health problems: a systematic review of primary care practitioners' perceptions. Br J Gen Pract. 2016;66(651):e693-707.

13. Lempp T, Heinzel-Gutenbrunner M, Bachmann C. Child and adolescent psychiatry: which knowledge and skills do primary care physicians need to have? A survey in general practitioners and paediatricians. Eur Child Adolesc Psychiatry. 2016;25(4):443-51.

14. Verhaak PF, van Dijk M, Walstock D, Zwaanswijk M. A new approach to child mental healthcare within general practice. BMC Family Practice. 2015;16(1):132.

15. Beers LS, Godoy L, John T, Long M, Biel MG, Anthony B, et al. Mental Health Screening Quality Improvement Learning Collaborative in Pediatric Primary Care. Pediatrics. 2017;140(6).

16. Roberts JH, Bernard PM. 'Can he have the test for bipolar, doctor? His dad's got it': exploring the potential of general practitioners to work with children and young people presenting in primary care with common mental health problems - a clinical initiative. Ment Health Fam Med. 2012;9(2):11523.

17. Gotovac S, Espinet S, Naqvi R, Lingard L, Steele M. Evaluating Training Programs for Primary Care Providers in Child/Adolescent Mental Health in Canada: A Systematic Review. Journal of the Canadian Academy of Child Adolescent Psychiatry = Journal de l'Academie canadienne de psychiatrie de l'enfant et de l'adolescent. 2018;27(2):99-111.

18. Hassink-Franke LJ, Janssen MM, Oehlen G, van Deurzen PA, Buitelaar JK, Wensing M, et al. GPs' experiences with enhanced collaboration between psychiatry and general practice for children with ADHD. Eur J Gen Pract. 2016;22(3):196-202.

19. Arbeitsgruppe Sozialpädiatrie des Berufsverbandes der. Kinder- und Jugendärzte e.V. (BVKJ). BKK Starke Kids Gesundheitsoaching. Handlungsleitfaden zur sozialpädiatrischen Sprechstunde für die Kinder- und Jugendärzte. 2016. 
20. World Health Organization. Classifications of Diseases 2020 [Available from: https://www.who.int/classifications/icd/en/.

21. Helfferich C. Die Qualität qualitativer Daten. Manual für die Durchführung qualitativer Interviews.: VS Verlag für Sozialwissenschaften; 2011.

22. Mayring P. Qualitative content analysis. In: Kardorff E, Steinke I, Flick U, editors. A companion to qualitative research. London: SAGE Publication; 2004. pp. 266-9.

23. Mayring P. Qualitative Inhaltsanalyse. Grundlagen und Techniken. 7 ed. Weinheim: Deutscher Studien Verlag; 2000.

24. World Health Organization. International Classification of Functioning, Disability and Health. Geneva: Children and Youth Version; 2007.

25. Schenk L, Ellert U, Neuhauser H. Kinder und Jugendliche mit Migrationshintergrund in Deutschland. Robert Koch-Institut, Epidemiologie und Gesundheitsberichterstattung; 2007.

26. Bühring P. Prävention psychischer Erkrankungen: Fokus auf die Risikogruppen. Dtsch Arztebl International. 2018;115(43):A-1942.

27. Gemeinsamer Bundesausschuss. Richtlinie des Gemeinsamen Bundesausschusses über die Früherkennung von Krankheiten bei Kindern (Kinder-Richtlinie). https://www.g-ba.de/downloads/62492-1998/Kinder-RL_2019-11-14_iK-2019-12-19.pdf; 2018.

28. Reardon T, Harvey K, Baranowska M, O'Brien D, Smith L, Creswell C. What do parents perceive are the barriers and facilitators to accessing psychological treatment for mental health problems in children and adolescents? A systematic review of qualitative and quantitative studies. European Child Adolescent Psychiatry. 2017;26(6):623-47.

29. Siebolds M, Münzel B, Müller R, Häußermann S, Paul M, Kahl C. Flächendeckende Implementierung von hilfesystemübergreifenden Qualitätszirkeln zum Thema Frühe Hilfen in Baden-Württemberg. Bundesgesundheitsblatt - Gesundheitsforschung - Gesundheitsschutz. 2016;59:1310-4.

30. Zimmermann T, Puschmann E, van den Bussche H, Wiese B, Ernst A, Porzelt S, et al. Collaborative nurse-led self-management support for primary care patients with anxiety, depressive or somatic symptoms: Cluster-randomised controlled trial (findings of the SMADS study). Int J Nurs Stud. 2016;63:101-11.

31. Bundesministerium für Gesundheit. Mitglieder und Versicherte der Gesetzlichen Krankenversicherung (GKV). Statistik über Versicherte, gegliedert nach Status, Alter, Wohnort und Kassenart (Stichtag: 1. Juli des jeweiligen Jahres). 20192020 [25.05.2020]. Available from: https://www.bundesgesundheitsministerium.de/themen/krankenversicherung/zahlen-und-faktenzur-krankenversicherung/mitglieder-und-versicherte.html.

\section{Figures}


Coding Tree: Interviews with Paediatricians

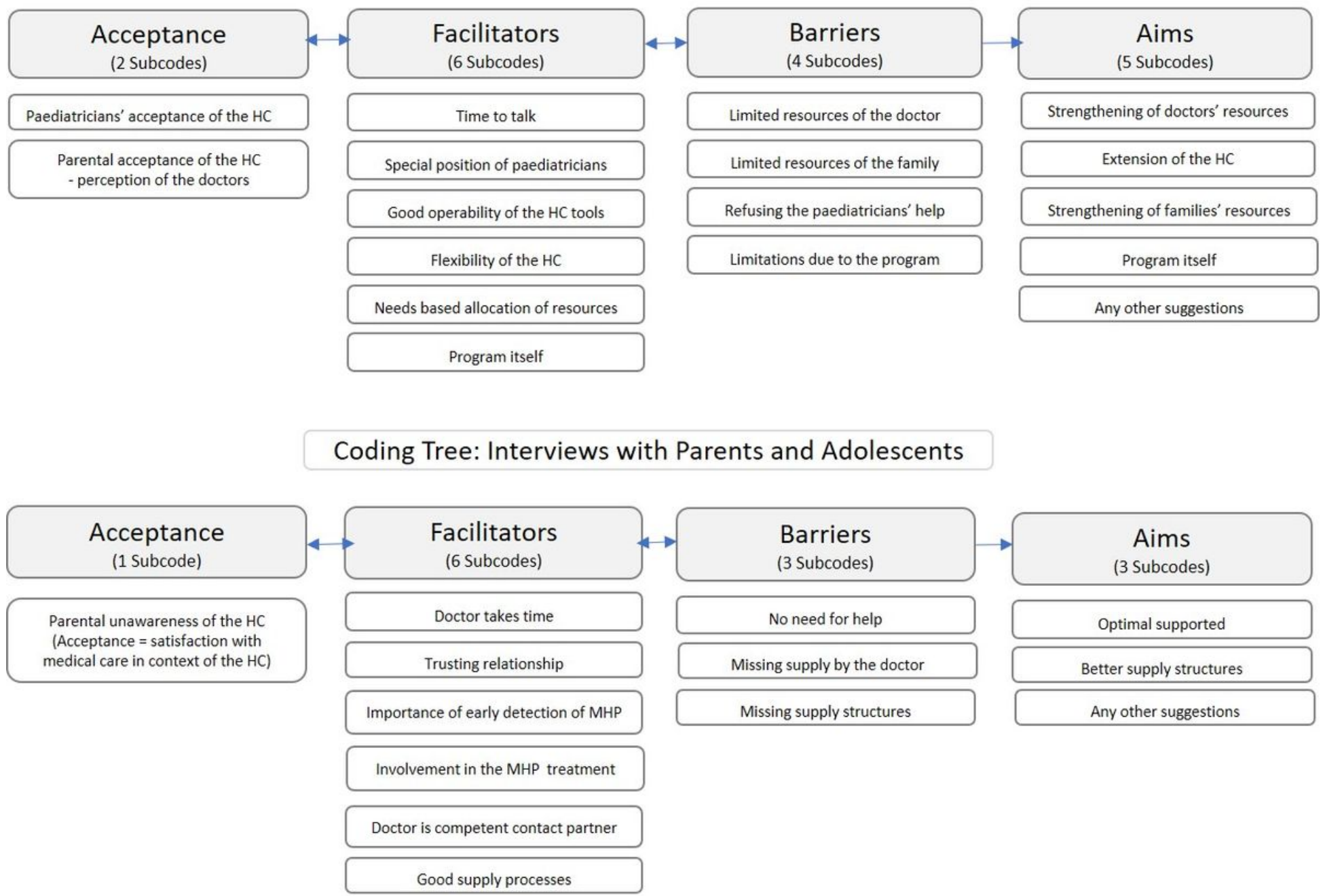

Figure 1

Extracted meta- and subcodes

\section{Supplementary Files}

This is a list of supplementary files associated with this preprint. Click to download.

- AdditionalFile1Supplementarylnformation.pdf

- AdditionalFile2COREQChecklist.pdf

- CoverletterlmplementationScience.pdf 